\title{
Fatores de satisfação com o uso de autônomos no transporte rodoviário de cargas
}

\author{
Peter Fernandes Wanke ${ }^{\text {** }}$ \\ a*peter@coppead.ufri.br, UFRJ, Brasil
}

\begin{abstract}
Resumo
No Brasil, o transporte de cargas é predominantemente rodoviário e depende fortemente da subcontratação de motoristas autônomos. Este artigo apresenta resultados de survey conduzido com 105 embarcadores - listados no Ranking Exame Melhores e Maiores - para avaliar os principais fatores relacionados à satisfação com os serviços prestados pelos autônomos, agrupando-se as empresas contratantes (embarcadores) em termos de necessidades comuns de serviço. Os resultados apontam para três grandes grupos de embarcadores, nos quais a qualidade de serviço percebida depende do uso intensivo de autônomos, do volume de carga transportado anualmente e do nível de exigência quanto à segurança dos carregamentos.
\end{abstract}

Palavras-chave

Fatores. Satisfação. Transporte de cargas. Autônomos. Segmentação.

\section{Introdução}

Atualmente, o transporte de cargas é destaque no Brasil devido à necessidade de uma estrutura logística adequada para sustentar o crescimento econômico do país. Estradas em bom estado de conservação, portos e ferrovias eficientes e aeroportos seguros são temas recorrentes na mídia nacional. Após longo período sem investimentos, o governo federal destinou $\mathrm{R} \$ 503,9$ bilhões à infraestrutura no período de 2007 a 2010, sendo $R \$ 58,3$ bilhões específicos para a área de logística (BRASIL, 2008). Por meio desses investimentos, a meta governamental é assegurar um crescimento econômico de 5\% ao ano entre 2008 e 2010 (YOSHIDA, 2007). Apesar dos significativos valores, ainda assim é questionável se os mesmos serão suficientes para eliminar todos os gargalos logísticos. Por exemplo, a Confederação Nacional do Transportes (CNT) elaborou um Plano de Logística para o Brasil que prevê a necessidade de investimentos mínimos de R\$ 405 bilhões (CONFEDERAÇÃO..., 2011).

A matriz de transporte brasileira mostra a seguinte distribuição entre os modais: $61,1 \%$ no rodoviário, $21 \%$ no ferroviário, $14 \%$ no aquaviário, 3,5\% no dutoviário e 0,4\% no aéreo (CONFEDERAÇÃO...,
2011). A predominância do modal rodoviário gera enormes problemas de produtividade devido às dimensões continentais do Brasil. Países de dimensões similares como EUA, Austrália e China transportam, respectivamente, $26 \%, 24 \%$ e $8 \%$ de sua carga pelo modal rodoviário (FLEURY, 2003a).

Soma-se a isto o fato de o transporte rodoviário ser tratado pelos órgãos públicos como um mercado livre. Dessa forma, não há legislação específica nem exigências para entrada e saída deste. As figuras de autorização, permissão e concessão não estão presentes nessa atividade (AGÊNCIA..., 2008a). 0 modal de transporte rodoviário destaca-se dos demais por possuir grande flexibilidade, uma vez que os veículos automotores podem operar em qualquer via disponível. A necessidade de poucos investimentos em ativos faz com que o transporte rodoviário seja muito atrativo para autônomos. Dados da Agência Nacional de Transportes Terrestres (ANTT) mostram que 46,2\% dos veículos cadastrados no Registro Nacional de Transporte Rodoviário de Cargas (RNTRC) pertencem aos autônomos, contra 53,1\% pertencentes às empresas e $0,71 \%$ às cooperativas (AGÊNCIA..., 2011). 
0 elevado percentual de autônomos atuando no transporte rodoviário de cargas faz com que suas práticas impactem profundamente o setor. As expectativas das empresas quanto aos serviços prestados, assim como sua satisfação, variam muito. lsso ocorre basicamente porque empresas com diferentes níveis de sofisticação logística empregam prestadores de serviço de características distintas (WANKE; ARKADER; HIJJAR, 2007). Os prestadores de serviço de transporte rodoviário podem até tentar adequar sua oferta às demandas de seus clientes, mas para tanto é necessário, primeiro, que os fatores de satisfação dos clientes quanto aos serviços prestados apresentem um padrão em comum. Descobrir se isso de fato ocorre no Brasil levou a definir o primeiro objetivo desta pesquisa: determinar se os embarcadores apresentam fatores de satisfação em comum com relação ao serviço prestado pelos transportadores rodoviários.

0 agrupamento dos embarcadores, com base nesses fatores (ou padrões) de satisfação, permitiria aos transportadores melhorar seu nível de serviço nos aspectos relevantes para cada segmento. Existem, no entanto, limitações técnicas e financeiras para se atender a todos os agrupamentos. A possibilidade de diferenciar os agrupamentos de embarcadores com base em características demográficas seria de grande utilidade, permitindo melhor posicionamento dos transportadores no mercado. Devido à ampla utilização de autônomos no transporte rodoviário de cargas, o percentual de carga transportada por esses profissionais foi a primeira característica escolhida para diferenciar os agrupamentos. A segunda característica foi escolhida por tratar-se de um dado relevante ao planejamento das operações de distribuição: a tonelagem transportada anualmente. Chega-se, assim, ao segundo objetivo desta pesquisa: determinar se é possivel distinguir os agrupamentos de embarcadores, originalmente gerados a partir de fatores de satisfação em comum, com base nessas duas características demográficas.

0 artigo está organizado em seis seções. A primeira seção apresenta uma visão geral do transporte rodoviário no Brasil, a relevância do tema e os objetivos do trabalho. A segunda seção traz a revisão de literatura. A terceira seção mostra as perguntas a serem respondidas, define o universo e a amostra, a forma como foram coletados os dados, a metodologia utilizada para análise e sua justificativa. A quarta seção analisa os resultados obtidos à luz da revisão de literatura. Já a quinta seção discute esses resultados. Por fim, a sexta seção encerra o artigo, com as conclusões alcançadas e sugestões para futuros estudos.

\section{Transporte de cargas e o uso de autônomos}

Chopra e Meindl (2006) afirmam que o transporte de cargas movimenta produtos por entre diversos pontos da cadeia de suprimentos, sendo um fator-chave para atingir maiores niveis de eficiência, velocidade e confiabilidade. Para os autores, a decisão fundamental é escolher entre o custo do transporte e a rapidez na entrega. Por exemplo, pode-se optar por um custo maior de transportes e maior agilidade ou por um custo menor e um prazo de entrega mais longo.

Os autores também analisam as características de desempenho de diferentes modais quanto aos tamanhos dos lotes transportados, aos estoques de segurança, aos estoques em trânsito, aos custos incorridos e aos tempos em trânsito. As relações entre essas características e os diferentes modais são apresentadas na Tabela 1, por meio de uma escala de 1 a 6 , na qual um menor valor indica menor custo, tempo ou estoque.

Especificamente com relação ao Brasil, Nazário (2000) afirma que, como cada vez mais se busca redução nos custos logísticos e maior confiabilidade no serviço prestado, o uso de mais de um modal (multimodalidade/intermodalidade) surge como oportunidade competitiva. Isso decorre da predominância do modal rodoviário na matriz de transportes brasileira, mesmo para produtos de baixo valor agregado em longas distâncias. Ainda em relação à competitividade do modal rodoviário, Fleury (2003b) enumera outros quatro grandes desafios, todos associados, em maior ou menor grau, ao uso de autônomos. Eles são detalhados a seguir.

Tabela 1. Impacto dos modais de transporte no desempenho da cadeia de suprimentos.

\begin{tabular}{|c|c|c|c|c|c|c|}
\hline & Ferroviário & $\begin{array}{c}\text { Rodoviário } \\
\text { (carga fechada) }\end{array}$ & $\begin{array}{l}\text { Rodoviário } \\
\text { (carga } \\
\text { fracionada) }\end{array}$ & $\begin{array}{l}\text { Entrega } \\
\text { expressa }\end{array}$ & Aéreo & Hidroviário \\
\hline Tamanho do lote & 5 & 4 & 3 & 1 & 2 & 6 \\
\hline Estoques de segurança & 5 & 4 & 3 & 1 & 2 & 6 \\
\hline Estoques em trânsito & 5 & 4 & 3 & 1 & 2 & 6 \\
\hline Custo do transporte & 2 & 3 & 4 & 6 & 5 & 1 \\
\hline Tempo de transporte & 5 & 3 & 4 & 1 & 2 & 6 \\
\hline
\end{tabular}




\subsection{Fragmentação do setor e expectativas de serviço}

Cerca de 50\% da frota nacional pertence a autônomos, 20\% a embarcadores e 30\% a transportadoras. Com relação às empresas de transporte, há em torno de 40.000 delas no Brasil, sendo que 85\% têm menos de 50 empregados. Apesar de poucos artigos tratarem do tema, percebe-se que essa fragmentação afeta sobremaneira não apenas as relações entre embarcadores e transportadores, mas também as expectativas e percepções com relação à qualidade dos serviços prestados.

Pesquisa realizada por Gibson, Rutner e Keller (2002), na qual os embarcadores estavam representados em sua maioria por fabricantes, evidenciou que o custo é o item de maior importância quando são consideradas parcerias com transportadores. Os embarcadores atribuíram ao custo maior importância com relação à sua satisfação na parceria. Tanto os embarcadores quanto os transportadores apresentaram um nível de satisfação extremamente baixo com relação ao desempenho da outra parte em controlar, reduzir e eliminar os custos da operação. Isso mostra que a relação entre embarcadores e transportadores carece de maior atenção, visto que não é possível que apenas uma das partes incorra em todos os esforços para redução de custos.

Hopkins et al. (1993), por sua vez, aplicaram questionário em embarcadores de diferentes indústrias e em empresas de transporte que utilizam os principais modais (aéreo, rodoviário, ferroviário e aquaviário). Os autores concluíram que um fator de grande importância para a satisfação com relação à qualidade do serviço prestado é o não cumprimento de promessas por parte dos transportadores.

Em linhas gerais, diferentes segmentos de clientes enfatizariam diferentes componentes do serviço logístico prestado por transportadores (MENTZER; FLINT; HULT, 2001). Entretanto, pode haver similaridades (fatores em comum) entre esses segmentos. Dessa forma, os gerentes de logística deveriam ser capazes de desenvolver processos aplicáveis a todos os segmentos. Por exemplo, a qualidade do contato pessoal teve impacto positivo na percepção do serviço em todos os segmentos estudados pelos autores. Os gerentes também deveriam ser capazes de avaliar quais são os aspectos mais relevantes para os segmentos que eles atendem. Caso existam fatores em comum, seria possível desenvolver recursos específicos para elevar a satisfação de todos os segmentos simultaneamente. E se as necessidades dos segmentos forem distintas, o gestor deveria buscar personalizar seu serviço para atender a um segmento específico. Esse tipo de procedimento não apenas habilitaria a logística a ser vista como uma vantagem competitiva, capaz de melhorar a eficiência por meio da redução de custos, mas também aprimoraria a eficiência do marketing na personalização de processos que gerem maior lucro para as empresas.

\subsection{Envelhecimento da frota por incapacidade de renovação}

A frota de caminhões no Brasil apresenta idade média de 18 anos. Além disto, 87\% das empresas transportadoras não adotam programas para renovar seus veículos. Candido (2004) afirma que a oferta excedente de frete, em decorrência de uma frota sucateada, contribui para deprimir os preços. Para garantir um volume mínimo de carga, o transportador autônomo acaba se sujeitando a trabalhar em condições inadequadas, muitas vezes em jornadas superiores às permitidas pela legislação, com excesso de carga e em velocidades exageradas ou inadequadas às condições de conservação das vias.

De fato, o setor encontra-se preso a um círculo vicioso. Pequenas barreiras de entrada e elevadas barreiras de saída geram mais oferta do que demanda (CENTRO..., 2002). 0 excesso de oferta faz com que os preços de frete caiam sistematicamente. Os transportadores passam, então, a ter maior dificuldade para captar carga. Pressionados por baixos preços e pela ociosidade, os autônomos passam a adotar práticas de concorrência predatória, como excesso de peso, de horas trabalhadas e de velocidade, além da crônica falta de manutenção adequada dos veículos. A capacidade disponível ofertada ao mercado aumenta em decorrência dessas práticas. Com maior oferta de transporte, o frete reduz-se ainda mais, retroalimentando esse círculo vicioso. Em síntese, a crônica dificuldade de renovação da frota reforça a relação de dependência dos embarcadores junto aos autônomos.

\subsection{Insegurança}

0 roubo de cargas vem aumentando sistematicamente no Brasil, sendo que em 2009 foram 13.500 ocorrências, contra 2.500 em 1994 e 7.500 em 2001. Esse problema, como era de se esperar, é mais grave em transportadores de menor porte, visto que eles afirmam ter muita dificuldade na administração dos seguros de carga. Mais precisamente, essas empresas com frequência se deparam com problemas na contratação de seguro contra roubo, basicamente por não possuírem políticas adequadas para gestão de risco (GAMEIRO; CAIXETA FILHO, 2002). 
Além disso, a maioria dos transportadores desconhece se as cargas contratadas estão efetivamente cobertas pelo seguro dos embarcadores. Do mesmo modo, com relação ao seguro obrigatório, verifica-se também essa falha de comunicação entre as duas partes (GAMEIRO; CAIXETA FILHO, 2002). Segundo os autores, como a grande maioria dos embarcadores não utiliza o seguro que lhes é obrigatório, maior responsabilidade recai necessariamente sobre os transportadores no caso de sinistros de carga.

0 roubo de cargas, quando comprovado ter sido caso de força maior, não mais é considerado responsabilidade do transportador. Nesses casos, o seguro do embarcador é que deve ressarci-lo das perdas ocasionadas. Por se tratar de seguro pouco utilizado, há grande pressão sobre os transportadores para que sejam responsabilizados pelo ocorrido. Por outro lado, em se confirmando a responsabilidade do transportador sobre a ocorrência do evento, seu seguro é que deve ser acionado (GAMEIRO; CAIXETA FILHO, 2002).

\subsection{Desregulamentação das relações de trabalho}

No Brasil, os transportadores autônomos frequentemente trabalham em parceria com as transportadoras, sendo contratados normalmente para suprir picos de demanda e para viajar longas distâncias (VALENTE; PASSAGLIA; NOVAES, 1997). Verifica-se ainda a utilização simultânea de motorista contratado pela empresa e de caminhoneiro autônomo para conferir maior flexibilidade na alocação de veículos e de rotas. Além disso, observa-se uma crescente complexidade nas relações de emprego, reforçada pela terceirização, a qual dissimula as relações de subordinação entre as partes. Contudo, ainda que as atividades desenvolvidas por motoristas e autônomos sejam praticamente as mesmas, não há um contrato formal de trabalho no último caso (CHAHAD; CACCIAMALI, 2005).

Também em outros países muitos motoristas têm passado da posição de empregados regulares para a situação de terceirizados, ou de autônomos, que devem dispor de seu próprio caminhão, ou mesmo alugá-lo, executando praticamente os mesmos serviços que realizavam quando regularmente empregados (INTERNATIONAL..., 2003). Na Alemanha, por exemplo, o número dos chamados motoristas independentes tem aumentado consideravelmente nos últimos anos. Na observância de um suposto "contrato de transporte", eles conduzem os caminhões em favor de um embarcador, ainda que sem direitos trabalhistas.
$\mathrm{Na}$ Argentina, a situação de um motorista autônomo tem sido considerada como a de um "trabalhador independente com posição de dependência”. Ademais, existe a prática de incentivar os motoristas a trabalharem como autônomos nas próprias empresas que os demitiram e das quais eles recebem incentivos para adquirir seu próprio veículo. Essa prática é conhecida na Finlândia como “empregadores involuntários". Muitos motoristas trabalham para o mesmo empregador, de quem alugam um caminhão segundo um plano de trabalho preestabelecido.

Nos “acordos de transporte" no Japão, o caminhoneiro autônomo é proprietário do veículo, sendo responsável pelas despesas de manutenção e pelo combustível, assim como outras taxas, incluindo a seguridade social. Muitos desses trabalhadores estão submetidos à forte relação de dependência, pois trabalham para uma única empresa. Por diversas vezes, o caminhão de propriedade do autônomo tem que ostentar claramente a marca ou o logotipo da empresa contratante.

Na Austrália, existem poucas barreiras ao ingresso de caminhoneiros autônomos no setor de transportes. Entretanto, o alto nível de endividamento contraído pelo caminhoneiro e o excesso de oferta favorecem o enfraquecimento de seu poder de barganha, aumentando sua situação de dependência. Como pode ser percebido, em praticamente todo mundo tem ocorrido uma substancial modificação das condições de trabalho desta categoria. Seu impacto nas relações de emprego desse setor depende fundamentalmente do ordenamento jurídico e da estrutura de custos de transporte de cada país.

Não obstante, também tem ocorrido a proliferação de empresas de subcontratação (quarteirização), o que garante a oferta de mão de obra e a prestação de serviços ao embarcador, mas acaba claramente encobrindo a relação de dependência que prevalecia até então. Esse fenômeno também contribui para desarticular ainda mais esse mercado de trabalho, na medida em que dificulta a organização sindical por parte dos autônomos (INTERNATIONAL..., 2003).

Nickerson e Silverman (2003) afirmam que a relação de emprego nas empresas transportadoras engloba uma "zona de tolerância" diferente daquelas observadas em relações contratuais tradicionais, referentes a outras formas de organização do trabalho. Percebe-se que os motoristas com vínculos de emprego regulares são mais fáceis de administrar do que os motoristas autônomos. Hart e Moore (1990) destacam que isso ocorre devido à propriedade do caminhão. A posse desse ativo resulta em diferentes posições de barganha quando o contrato se rompe. Essa diferença no poder de barganha afeta a cooperação e o relacionamento 
entre a empresa e o autônomo, significando que a "zona de tolerância" não é resultado do estado mental de ambas as partes, mas decorrente da posse do ativo físico, no caso, o caminhão.

Segundo Chahad e Cacciamali (2005), embora a propriedade do caminhão não seja mais da empresa, transformando-se num instrumento de trabalho do caminhoneiro, ela representa a utilização de uma forma de capitalização mais flexível, cujo investimento e manutenção foram repassados para o autônomo. Segundo os autores, a ocorrência de diferentes arranjos trabalhistas, decorrente da busca por maior eficiência no transporte de cargas, não deixa de implicar relações de emprego dissimuladas, caracterizadas por dependência direta ao embarcador.

\section{Objetivos e metodologia}

Observando-se o objetivo principal desta pesquisa, que é determinar se os embarcadores apresentam fatores de satisfação em comum no transporte rodoviário de cargas, apresentamos a primeira pergunta:

1. Os embarcadores apresentam fatores de satisfação em comum com relação ao serviço de transporte que lhes é prestado?

Para responder essa pergunta, foi elaborada a seguinte hipótese nula:

HO 1: Os embarcadores não apresentam fatores de satisfação em comum com relação ao transporte rodoviário de cargas.

Observando-se o segundo objetivo principal, que é agrupar os embarcadores com base nesses fatores de satisfação em comum, apresentamos a segunda pergunta:

2. Os embarcadores podem ser segmentados em função da tonelagem transportada anualmente e do percentual de movimentação de cargas efetuado via autônomos?

Para responder essa pergunta, relevante por eventualmente possibilitar um posicionamento de mercado mais adequado por parte dos transportadores, foi elaborada a seguinte hipótese nula:

HO 2: A tonelagem transportada anualmente e o percentual de transporte efetuado com autônomos não diferenciam os segmentos de embarcadores constituídos a partir dos fatores de satisfação em comum.

0 universo desta pesquisa compõe-se de todos os embarcadores de cargas no modal rodoviário. Devido ao grande número de empresas que compõe essa população, abrangendo os mais diversos portes, ramos de atividades e práticas administrativas, houve a necessidade de limitar a amostra. Para a definição da amostra, partiu-se, inicialmente, dos 379 embarcadores de carga rodoviária listados entre as 1.000 maiores empresas do Brasil, conforme ranking divulgado pela revista Exame.

Antes do envio dos questionários, foi efetuado contato telefônico com as empresas-alvo explicando os objetivos da pesquisa e consultando-as sobre seu desejo em participar. Esse procedimento se justifica tendo em vista que o número de contatos, contatos personalizados e contatos prévios é frequentemente associado às altas taxas de resposta em pesquisas conduzidas pela internet (COOK; HEATH; THOMPSON, 2000). Ao final dessa fase inicial de contatos, 379 empresas se dispuseram a responder o questionário.

0 questionário foi elaborado em planilha Excel. 0 mesmo foi enviado anexado a um e-mail com as orientações sobre os objetivos da pesquisa e sobre o preenchimento da planilha. Durante o período de coleta dos dados foram feitos diversos contatos telefônicos com as empresas, visando aumentar a taxa de respostas. Ao término do período de coleta, 113 questionários haviam sido recebidos. Destes, dois foram descartados por não terem seus dados validados. Dos questionários restantes, outros seis foram eliminados por não possuírem todas as respostas que tratam da satisfação com os transportadores de cargas pelo modal rodoviário, o que inviabilizava seu uso nas análises que se seguiram. Dessa forma, restaram 105 questionários, perfazendo um total de 27,7\% de respostas válidas.

As pesquisas conduzidas por meio do envio de correspondências são alvo de críticas quanto à possibilidade de substanciais diferenças entre os perfis dos respondentes e dos não respondentes. A melhor forma de minimizar esse erro é manter a porcentagem de não respondentes abaixo de 30\% (ARMSTRONG; OVERTON, 1977).

Como a pesquisa obteve uma taxa de não respondentes acima deste valor, optou-se por comparar as características demográficas conhecidas do universo com as características da amostra. Isso foi feito por meio da tabulação cruzada da distribuição de frequências, pelas diferentes indústrias, dos dados da amostra e do universo considerado (Ranking Exame). Os testes utilizados foram o gamma de Goodman e Kruskal, tau-b de Kendall e o tau-c de Kendall (RODRIGUES; STANK; LYNCH, 2004).

As distribuições das empresas entre os diversos segmentos industriais, tanto no universo como na amostra, são apresentadas na Tabela 2.

Os testes de correlação não paramétricos tau-b e tau-c de Kendall e gamma de Kruskal mostraram-se significativos, assegurando que a amostra é aderente 
à população e que, dessa forma, não há diferenças significativas entre ambas as distribuições (cf. Tabela 3).

Finalmente, a nomenclatura das variáveis coletadas, as dimensões avaliadas e o tipo de escala, com sua descrição, são apresentados na Quadro 1.

\section{Análise dos resultados}

\subsection{Padrões comuns de satisfação}

0 primeiro passo foi verificar se a variável que trata a percepção da satisfação dos embarcadores com a média dos transportadores (variável 1) se relaciona com a percepção de satisfação acerca de diferentes aspectos do serviço prestado (variáveis 2 a 15). Foi utilizado o teste de correlação não paramétrica tau-b de Kendall por tratar-se de um teste mais apropriado, permitindo uma correlação mais acurada

Tabela 2. Distribuições das empresas entre as indústrias.

\begin{tabular}{|c|c|c|}
\hline Indústria & $\begin{array}{c}\text { População (M\&M } \\
1.000)\end{array}$ & Amostra \\
\hline Alimentos, Bebidas e Fumo & 116 & 13 \\
\hline Atacado e Comércio Exterior & 84 & 8 \\
\hline Automotivo & 51 & 10 \\
\hline Comércio Varejista & 66 & 5 \\
\hline Comunicações & 12 & 2 \\
\hline Confecções e Têxteis & 25 & 7 \\
\hline Construção & 22 & 0 \\
\hline Diversos & 13 & 0 \\
\hline Eletroeletrônicos & 45 & 7 \\
\hline $\begin{array}{l}\text { Farmacêutico, Higiene e } \\
\text { Cosméticos }\end{array}$ & 32 & 7 \\
\hline Limpeza & 2 & 1 \\
\hline Material de Construção & 26 & 5 \\
\hline Mecânica & 16 & 1 \\
\hline Mineração & 16 & 1 \\
\hline Outros & 1 & 0 \\
\hline Papel e Celulose & 19 & 8 \\
\hline Plásticos e Borracha & 16 & 0 \\
\hline Química e Petroquímica & 87 & 12 \\
\hline Serviços de Transporte & 38 & 0 \\
\hline Serviços Diversos & 61 & 0 \\
\hline Serviços Públicos & 118 & 0 \\
\hline Siderurgia e Metalurgia & 69 & 13 \\
\hline Tecnologia e Computação & 29 & 2 \\
\hline Telecomunicações & 36 & 3 \\
\hline Total $=>$ & 1.000 & 105 \\
\hline
\end{tabular}

Tabela 3. Tabulação cruzada entre amostra e população.

\begin{tabular}{ccc}
\hline Teste & Valor & Significância \\
\hline Kendall's tau-b & 0,398 & 0,011 \\
Kendall's tau-c & 0,397 & 0,011 \\
Gamma & 0,424 & 0,011 \\
\hline
\end{tabular}

do que o teste de Spearman (FIELD, 2005). Como buscamos comprovar se o aumento da satisfação afeta positivamente a percepção do desempenho dos transportadores, foi utilizado um teste unicaudal, também, chamado direcional (WITTE; WITTE, 2005).

0 resultado do teste de correlação não paramétrica tau-b de Kendall apresentou correlações significativas para todas as variáveis analisadas em relação à percepção do desempenho médio dos transportadores. A variável área geográfica de atuação mostrou-se significativa a 0,05 . As demais variáveis mostraram-se significativas a 0,01 .

As correlações significativas foram tratadas estatisticamente por meio da técnica de análise fatorial, buscando-se determinar se havia relações entre as mesmas e permitindo a formação de fatores de satisfação comuns aos embarcadores. Foi realizada uma análise fatorial do tipo $\mathrm{R}$, que procurou encontrar correlações entre as variáveis. 0 método utilizado foi o de componentes principais, por tratar-se de pesquisa exploratória de dados para a geração de hipóteses (FIELD, 2005). Além disto, esse método apresenta mais facilidade de processamento quando comparado com outros disponíveis, encontrando-se resultados semelhantes na maioria dos casos em que há mais de 30 variáveis ou as comunalidades excederem 0,60 para a maioria das variáveis (HAIR; ANDERSON, TATHAM, 2005). Para determinar o número de fatores a ser extraído, optou-se pelo critério do teste scree. Utiliza-se o teste scree para determinar o ponto em que a variância única dos fatores passa a dominar a estrutura de variância comum. Esse critério foi preferido ao critério eigenvalue devido ao número de variáveis, pois, para menos de 20 variáveis, como é o caso desta pesquisa, o critério eigenvalue resulta em um número conservador de fatores.

Finalmente, como forma de tornar essa opção mais robusta, foi observada a percentagem de variância. A determinação do número de fatores pela quantidade de variância explicada calcula o acúmulo da variância para cada fator extraído até que se atinja um nível satisfatório. Dessa forma, foi verificado se os fatores extraídos pelo critério do teste scree possuíam a variância mínima de $60 \%$, recomendada pela literatura (MALHOTRA, 2001).

Após a determinação do número de fatores, os dados foram rotacionados. Esse procedimento se justifica uma vez que, na maioria dos casos, ajuda a diminuir ambiguidades na interpretação dos fatores. Havendo a opção por rotações oblíquas e ortogonais, optou-se por esta última devido à existência de controvérsias sobre os procedimentos analíticos das rotações oblíquas, além destes ainda não estarem bem desenvolvidos (HAIR; ANDERSON; TATHAM, 2005). Dentre os métodos disponíveis de rotação ortogonal, 
adotou-se o varimax por sua característica de procurar relacionar variáveis possuidoras de cargas altas em um único fator (SHARMA, 1996). lsso resulta em fatores cuja interpretação é mais simples (FIELD, 2005).

Os quatro fatores extraídos explicam 64,31\% da variância. 0 teste $\mathrm{KMO}$ teve como resultado 0,839, o que é considerado um resultado notável e comprova a possibilidade de gerar fatores distintos e confiáveis. Por sua vez, o teste de esfericidade de Bartlett teve significância inferior a 0,000, rejeitando a existência de uma matriz identidade e permitindo a análise. Também cabe ressaltar que, das 14 variáveis analisadas, 10 mostraram comunalidades superiores a 0,6 , comprovando a adequação da análise de componentes principais.
Finalmente, todas as variáveis apresentaram cargas fatoriais superiores a $0,55 \mathrm{em}$ pelo menos um fator. Nenhum fator foi composto por apenas uma variável. Dessa forma, todas as variáveis foram incluídas na análise. Os resultados são apresentados na Tabela 4.

Os quatro fatores encontrados foram interpretados e nomeados de forma a indicar o seu significado, conforme apresentado a seguir.

- Fator 1 - Sinergia: Compreende as atividades de inteligência por parte do transportador, que oferece ao embarcador não só o transporte em si, mas melhorias no seu serviço;

- Fator 2 - Confiabilidade: Caracterizado pelo desempenho do transportador na execução direta do serviço contratado;

Quadro 1. Variáveis coletadas e escalas utilizadas.

\begin{tabular}{|c|c|c|c|}
\hline Dimensão & Variáveis & Escala adotada & $\begin{array}{l}\text { Tipo de } \\
\text { escala }\end{array}$ \\
\hline \multicolumn{4}{|c|}{ Hipótese 1} \\
\hline & 1. Desempenho médio de todos os transportadores & $\begin{array}{l}1 \text { (menor satisfação) a } \\
10 \text { (maior satisfação) }\end{array}$ & Ordinal \\
\hline $\begin{array}{c}\text { Satisfação em relação } \\
\text { aos transportadores }\end{array}$ & $\begin{array}{l}\text { 2. Disponibilidade de veículos e equipamentos } \\
\text { 3. Preço cobrado } \\
\text { 4. Condições de veículos e equipamentos } \\
\text { 5. Consistência nos prazos } \\
\text { 6. Rapidez } \\
\text { 7. Integridade da carga } \\
\text { 8. Qualificação de pessoal } \\
\text { 9. Variedade de serviços oferecidos } \\
\text { 10. Soluções propostas para melhoria das atividades } \\
\text { 11. Sofisticação tecnológica } \\
\text { 12. Área geográfica de atuação } \\
\text { 13. Disponibilidade de informações gerenciais } \\
\text { 14. Histórico de não envolvimento em acidentes } \\
\text { 15. Histórico de não envolvimento em roubos }\end{array}$ & $\begin{array}{l}1 \text { - Satisfação muito alta } \\
2 \text { - Satisfação alta } \\
3 \text { - Satisfação média } \\
4 \text { - Satisfação baixa } \\
5 \text { - Satisfação muito baixa }\end{array}$ & Ordinal \\
\hline \multicolumn{4}{|c|}{ Hipótese 2} \\
\hline Volume da operação & 16.Tonelagem transportada anualmente pelo modal rodoviário & 0 a 100 & Razão \\
\hline Propriedade da frota & 17. Percentual da carga rodoviária transportada por autônomos & 0 a 100 & Razão \\
\hline
\end{tabular}

Tabela 4. Matriz rotacionada de componentes.

\begin{tabular}{|c|c|c|c|c|}
\hline \multirow{2}{*}{ Variável } & \multicolumn{4}{|c|}{ Componentes } \\
\hline & Fator 1 & Fator 2 & Fator 3 & Fator 4 \\
\hline Percentual explicado da variância pelo fator & $19,86 \%$ & $19,20 \%$ & $12,99 \%$ & $12,26 \%$ \\
\hline Disponibilidade de veículos e equipamentos & 0,023 & 0,604 & $-0,045$ & 0,556 \\
\hline Preço cobrado & 0,098 & 0,228 & 0,126 & 0,739 \\
\hline Condições de veículos e equipamentos & 0,379 & 0,637 & $-0,148$ & 0,047 \\
\hline Consistência de prazos & 0,104 & 0,699 & 0,298 & 0,066 \\
\hline Rapidez & 0,211 & 0,727 & 0,174 & 0,130 \\
\hline Integridade da carga & 0,114 & 0,565 & 0,131 & 0,277 \\
\hline Qualificação de pessoal & 0,410 & 0,327 & 0,145 & 0,556 \\
\hline Variedade dos serviços oferecidos & 0,710 & 0,079 & 0,174 & 0,116 \\
\hline Soluções propostas & 0,642 & 0,444 & 0,213 & 0,117 \\
\hline Sofisticação tecnológica & 0,757 & 0,380 & 0,100 & 0,090 \\
\hline Área geográfica de atuação & 0,497 & $-0,075$ & 0,055 & 0,590 \\
\hline Disponibilidade de informações gerenciais & 0,771 & 0,122 & 0,092 & 0,219 \\
\hline Histórico de não envolvimento em acidentes & 0,135 & 0,221 & 0,858 & 0,112 \\
\hline Histórico de não envolvimento em roubos & 0,205 & 0,067 & 0,887 & 0,083 \\
\hline
\end{tabular}


- Fator 3 - Gerenciamento de riscos: Consistência do transportador em evitar incidentes que causam prejuízo ao embarcador; e

- Fator 4 - Qualificadores: Requisitos mínimos que devem ser oferecidos pelo transportador, sem os quais o embarcador não aceita contratá-lo.

Os fatores 1, 2, 3 e 4 apresentaram valores para o alfa de Cronbach de 0,$821 ; 0,764 ; 0,828$ e 0,635 , respectivamente. Como todos os fatores apresentaram um alfa de Cronbach superior a 0,6, os mesmos foram considerados validados. As correlações inter-item nos fatores 1,2 e 3 formam superiores a 0,3 . No fator 4 , a relação entre as variáveis preço cobrado e área geográfica de atuação foi de 0,243, inferior a 0,3. Porém, como o valor do alfa de Cronbach para o fator foi aceitável, o fator foi considerado validado. 0 último passo da análise fatorial consiste no cálculo dos escores fatoriais. Esse procedimento foi importante, pois omB e 24 ( $22,86 \%$ dos casos) no cluster C. Os respectivos centroides são apresentados na Tabela 5 .

Pelo resultado do teste Mann-Withney, os centroides do cluster B diferenciam-se dos demais clusters em todos os fatores. Sabemos também, pelo mesmo teste, que os clusters $\mathrm{A}$ e $\mathrm{C}$ diferem apenas no fator 3. Os diferentes níveis de satisfação apresentados pelos clusters têm ligação direta com as expectativas dos embarcadores que os compõem. Um valor elevado na satisfação de cada fator pode ser resultado de um nível de serviço alto prestado pelo transportador ou de expectativas baixas por parte do embarcador.

A análise de cada agrupamento nos permite concluir que o cluster $B$ recebe os piores serviços e tem o menor custo repassado pelos transportadores. Entretanto, por possuir as menores expectativas

As variáveis destacadas correspondem aos fatores. Tabela 5. Centroides dos clusters.

\begin{tabular}{lccc}
\hline \multicolumn{1}{c}{ Fatores } & A & B & C \\
\hline Fator 1 - Sinergia & 2,47 & 1,65 & 2,38 \\
Fator 2 - Confiabilidade & 1,60 & 1,31 & 1,68 \\
Fator 3 - Gerenciamento de riscos & 1,73 & 1,43 & 2,84 \\
Fator 4 - Qualificadores & 1,71 & 1,38 & 1,79 \\
\hline
\end{tabular}

quanto ao serviço, apresenta a maior satisfação média, podendo ser chamado de Tolerante (cf. Tabela 6).

Já o cluster A tem maior expectativa em relação aos fatores sinergia, confiabilidade e gerenciamento de riscos. Com isso, a satisfação nesses três fatores é menor em relação ao cluster Tolerante. Para atender as necessidades das empresas que compõem esse cluster, os transportadores exigem um preço-prêmio, o que faz com que a satisfação com relação ao fator qualificador também decresça. Esse cluster foi denominado como Exigente.

O cluster $\mathrm{C}$ tem comportamento semelhante ao cluster Tolerante em relação aos fatores sinergia, confiabilidade e qualificadores. A expectativa das empresas desse cluster em relação ao fator gerenciamento de risco é maior do que nos clusters Tolerante e Exigente. Essas características fazem com que a satisfação em relação ao fator gerenciamento de risco decresça de forma análoga, porém mais acentuada, ao que ocorre com o cluster Exigente. Esse cluster apresenta a pior satisfação média. Tendo em vista a peculiaridade do cluster em relação ao fator gerenciamento de risco e a provável maior exigência com relação ao mesmo, esse agrupamento foi denominado Protetor.

\subsection{Diferenciação dos agrupamentos}

Segundo Hair, Anderson e Tatham (2005), para verificar se as variáveis indicadas na hipótese 2 diferenciam os agrupamentos, podem ser utilizadas a análise discriminante múltipla ou a regressão logística multinomial. Ambas são adequadas quando a variável dependente é categórica (com três ou mais grupos) e as variáveis independentes são métricas.

Os mesmos autores ressaltam que a utilização da análise discriminante depende da existência de normalidade multivariada e de matrizes de variância-covariância iguais. Quando esses pressupostos não são satisfeitos, a regressão logística mostra-se muito mais robusta. Além disso, pode aceitar variáveis não métricas desde que codificadas na forma de variáveis dicotômicas (dummy). Esses motivos justificaram a opção pela regressão logística

Tabela 6. Interpretação dos clusters de satisfação.

\begin{tabular}{|c|c|c|c|c|c|c|}
\hline \multirow[b]{3}{*}{ Fator 1 - Sinergia } & \multicolumn{6}{|c|}{ Centroides dos clusters } \\
\hline & \multicolumn{2}{|c|}{$\begin{array}{c}\text { (A) } \\
\text { Exigentes }\end{array}$} & \multicolumn{2}{|c|}{$\begin{array}{c}\text { (B) } \\
\text { Tolerantes }\end{array}$} & \multicolumn{2}{|c|}{$\begin{array}{c}\text { (C) } \\
\text { Protetores }\end{array}$} \\
\hline & 2,47 & $\mathrm{R}$ & 1,65 & $\mathrm{~S}$ & 2,38 & $\mathrm{R}$ \\
\hline Fator 2 - Confiabilidade & 1,60 & $\mathrm{~S}$ & 1,31 & MS & 1,68 & $\mathrm{~S}$ \\
\hline Fator 3 - Gerenciamento de riscos & 1,73 & $\mathrm{~S}$ & 1,43 & MS & 2,84 & $\mathrm{R}$ \\
\hline Fator 4 - Qualificadores & 1,71 & $\mathrm{~S}$ & 1,38 & MS & 1,79 & $\mathrm{~S}$ \\
\hline Média dos fatores & 1,88 & $\mathrm{~S}$ & 1,44 & MS & 2,17 & $\mathrm{R}$ \\
\hline
\end{tabular}

Interpretação da satisfação: $\mathrm{R}$ = regular, $\mathrm{S}$ = satisfeito, $\mathrm{MS}$ = muito satisfeito. 
multinomial. A significância máxima adotada para os testes foi de 0,10 por se tratar de estudo exploratório (MENTZER; FLINT, 1997).

Os resultados da análise de regressão apresentados na Tabela 7 indicam que as variáveis total de carga transportada (em toneladas, pelo modal rodoviário) e percentual de carga transportada por autônomos apresentaram significância satisfatória (abaixo de 0,10), mostrando que as mesmas discriminam os clusters. De fato, o teste de razão de verossimilhança para o modelo final apresentou significância de 0,014. Esse resultado evidencia a adequação da combinação entre as variáveis explicativas e os clusters.

\section{Discussão dos resultados}

Os fatores analisados englobam tanto o custo quanto as características dos serviços prestados, elementos fundamentais nas decisões gerenciais de transporte. Também englobam as principais dimensões desse tipo de serviço: velocidade, consistência, capacitação, disponibilidade e frequência.

0 primeiro fator, sinergia, refere-se aos serviços prestados pelo transportador em sintonia com o embarcador, agregando valor às suas atividades. A competição que caracteriza o mercado brasileiro, e faz com que os preços caiam, não deixa margem para que o transportador pague seus custos, execute essas atividades de valor agregado e ainda obtenha lucro. Dessa forma, podemos inferir que a expectativa dos embarcadores deveria ser modesta. Isso parece ocorrer no cluster Tolerante. No entanto, os clusters Exigente e Protetor apresentam um grau de satisfação regular. Podemos concluir que ambos possuem maior expectativa e, consequentemente, uma zona menor de tolerância quanto à sinergia no transporte de cargas.

0 segundo fator, confiabilidade, refere-se a indicadores básicos do serviço de transporte. Como no fator anterior, a competição agressiva reduzindo preços faz com que as expectativas pelo nível de serviço sejam baixas. Por outro lado, esses indicadores são mais facilmente atingiveis, exigindo-se menor dispêndio de recursos por parte do transportador.
Como consequência, os clusters Exigente e Protetor apresentam-se satisfeitos e o cluster Tolerante, muito satisfeito. Podemos inferir que o cluster Tolerante tem expectativas menores do que as dos clusters Exigente e Protetor.

0 terceiro fator, gerenciamento de riscos, padece dos mesmos problemas que os fatores anteriores em função da competição, não sendo comum no Brasil a adoção de seguros que protejam as cargas. Quanto a esse fator, o cluster Tolerante mostra-se muito satisfeito, o cluster Exigente, satisfeito, e o cluster Protetor, com satisfação regular. Podemos inferir que o cluster Protetor é o que possui maiores expectativas quanto ao gerenciamento de riscos por parte do transportador.

0 quarto fator, qualificadores, contém os indicadores que, se não alcançarem patamar mínimo, impedem a contratação do serviço. Nesse caso, os clusters Exigente e Protetor estão satisfeitos e o cluster Tolerante está muito satisfeito. Tratando-se especificamente desse fator, inferimos que o cluster Tolerante paga valores reduzidos, o que gera maior satisfação. Os clusters Exigente e Protetor devem pagar valores mais elevados pelo serviço prestado. É importante ressaltar que esse fator faz referência ao custo do frete, mas não aborda diretamente outros custos relevantes na escolha da rede de transportes como os custos de estoques, instalações, processamento de pedido e nível de serviço.

Observando os resultados da análise de regressão logística, apresentados na Tabela 7, pode-se montar o seguinte sistema de equações, o qual fornece as respectivas probabilidades de se pertencer a determinado cluster com base nas variáveis total de carga transportada (TotalCarga) e percentual de carga transportada por autônomos (PercAut):

Exigente: $=\mathrm{e}^{(0,087-0,015 \text { PercAut }+0,0001 \text { Total Carga })}$

Protetor: $=\mathrm{e}^{(0,087-0,015 \text { PercAut }+0,0001 \text { Total Carga })}$

Tolerante: $=-\mathrm{e}^{(0,087-0,015 \text { PercAut }+0,0001 \text { Total Carga })}$

- e(-0,397-0,032 PercAut + 0,0001 Total Carga)

Tabela 7. Regressão logística multinomial.

\begin{tabular}{|c|c|c|c|c|c|c|}
\hline Cluster & Variável & B & Erro padrão & Wald & $\begin{array}{l}\text { Graus de } \\
\text { liberdade }\end{array}$ & Significância \\
\hline \multirow{3}{*}{ Exigente } & Constante & 0,087 & 0,361 & 0,058 & 1 & 0,809 \\
\hline & \% Transp. por autônomos & $-0,015$ & 0,009 & 2,840 & 1 & 0,092 \\
\hline & Total carga transp. (ton.) & 0,0001 & 0,000 & 4,056 & 1 & 0,044 \\
\hline \multirow{3}{*}{ Protetor } & Constante & $-0,397$ & 0,416 & 0,911 & 1 & 0,340 \\
\hline & \% Transp. por autônomos & $-0,032$ & 0,015 & 4,648 & 1 & 0,031 \\
\hline & Total carga transp. (ton.) & 0,0001 & 0,000 & 3,749 & 1 & 0,053 \\
\hline
\end{tabular}


Para a análise que se segue, deve ser observado que conclusões válidas são obtidas somente para a região do espaço em que as três probabilidades somadas são necessariamente iguais a 1, e cada uma, individualmente, é maior ou igual que 0 e menor ou igual a 1 .

Analisando-se em termos do total de carga transportada, para diferentes percentuais de uso de autônomos, vemos que os Tolerantes têm, em comparação com os outros clusters, maior probabilidade de movimentar pequenos volumes até, aproximadamente, 400 t. Essa probabilidade continua a decrescer até aproximar-se de 0 em torno de $12.000 \mathrm{t}$. Esse cluster também tem a menor probabilidade de utilizar uma pequena proporção de autônomos para transportar suas cargas. No entanto, o segmento apresenta as maiores probabilidades quando temos a proporção de cerca de $90 \%$ a $100 \%$ da carga transportada por autônomos. Os motivos que levam empresas com menor volume de carga transportada a ter menor expectativa podem ser atribuídos ao baixo impacto que a movimentação de pequenos volumes tem nos custos totais da empresa. Quanto maior a escala, maior o custo e, consequentemente, a preocupação com questões operacionais. Essa ausência de preocupação com a atividade de transporte também é refletida na utilização de autônomos em maior proporção. Uma vez que as empresas não se preocupam com o nível de serviço prestado, seu objetivo passa a ser o menor custo possível, o que é encontrado com os transportadores autônomos.

Os Exigentes são o agrupamento que tem maior probabilidade de transportar cargas a partir de cerca de $400 \mathrm{t}$ anuais. Quanto ao emprego de autônomos, os Exigentes têm a maior probabilidade de utilizá-los desde que eles sejam responsáveis de $0 \%$ até cerca de $90 \%$ da carga transportada. Por ter a maior probabilidade de movimentar grandes volumes, este agrupamento apresenta as maiores expectativas quanto ao serviço prestado. 0 impacto dessa atividade nos custos totais deve ser bem maior nesse segmento do que nos outros.

Os Protetores têm a menor probabilidade de movimentar pequenos volumes (até cerca de $1.600 \mathrm{t}$ anuais). As chances de movimentar um maior volume aumentam até cerca de $6.000 \mathrm{t}$, quando começam a decrescer. Quanto aos transportadores autônomos, esse segmento apresenta as menores probabilidades para níveis de utilização entre 20\% e 100\%. Apesar das várias semelhanças que os Protetores guardam em relação aos Exigentes quanto às suas expectativas, as diferenças entre eles nos permitem inferir conclusões interessantes. A probabilidade de pertencer ao grupo dos Protetores, em função da movimentação, cresce até aproximadamente $6.500 \mathrm{t}$, quando começa a diminuir. Isso representa uma limitação no volume transportado, possivelmente por ter maior valor agregado. Além disso, esse agrupamento é o que apresenta a menor probabilidade de utilizar-se de autônomos, provavelmente pela busca de maior segurança em função do perfil de carga transportada.

\section{Conclusões e sugestões para pesquisas futuras}

0 mercado de transporte rodoviário de cargas no Brasil segue uma prática encontrada em vários países do mundo, a saber: a utilização de profissionais autônomos como forma de reduzir custos e evitar a existência de relações trabalhistas mais dispendiosas. Embora os motivos que levam as empresas a utilizar autônomos ao redor do mundo variem pouco, no Brasil, peculiaridades como a ausência de barreiras à entrada e grandes dificuldades ao tentar abandonar a indústria criaram uma situação inusitada, na qual um círculo vicioso afeta todo o setor, comprometendo margens e nível de serviço.

Apesar das características desse mercado - no qual a disputa por custos é acirrada e os outros modais não representam ameaça significativa -, esta pesquisa demonstrou que nem todos os embarcadores possuem as mesmas expectativas quanto ao serviço que recebem e, dessa forma, comportam-se de forma distinta. Esses resultados podem contribuir no sentido de auxiliar não apenas os transportadores, em decisões relativas à segmentação dos mercados e ao desenho de serviços personalizados de transporte de cargas, mas também os embarcadores, com relação a um entendimento melhor de suas expectativas e principais critérios para avaliação desse serviço.

Mais especificamente, os resultados da pesquisa indicam que os embarcadores se agrupam em três diferentes segmentos (Protetor, Tolerante e Exigente) a partir de fatores de satisfação em comum (sinergia, confiabilidade, gerenciamento de riscos e qualificadores). Além de diferenças com relação à tolerância a níveis de serviço menores e à aversão ao risco de roubo de cargas, os resultados também indicam que esses segmentos se diferenciam pela tonelagem transportada anualmente e pelo percentual de transporte efetuado com autônomos.

Em linhas gerais, parece que a maior utilização de autônomos está relacionada a segmentos nos quais o volume movimentado é pequeno e por isso o percentual de autônomos pode ser maior, sem implicar maiores riscos para a operação de transporte. Por outro lado, percebe-se que maior volume transportado acarreta maiores expectativas com relação aos níveis de serviço e aos riscos da operação, levando, necessariamente, a 
uma progressiva redução no percentual de autônomos. É de se esperar que, com o continuo crescimento da economia a se verificar nos próximos anos, o segmento Tolerante tenda a desaparecer, não apenas em função de uma maior escala da operação (ou seja, maiores volumes transportados), mas também em virtude do acirramento da concorrência de outros embarcadores e do investimento em infraestrutura em outros modais de transporte.

Esse cenário, no qual o Exigente tende a predominar, traz consequências, como a necessidade de maior profissionalização do setor de transporte rodoviário de cargas para se manter competitivo. É provável que a figura solitária do autônomo acabe desaparecendo ao longo do tempo ou, pelo menos, fique cada vez mais dependente da subcontratação por empresas de transporte de cargas. Essas, por sua vez, deverão experimentar, por conta do crescimento econômico e pressões competitivas, uma onda de fusões e aquisições - assim como é verificada nos demais setores da economia -, de modo a conseguir aumentar simultaneamente a escala da operação e 0 escopo dos serviços prestados, mantendo a eficiência em custos.

Como principal limitação desta pesquisa, além de sugestão para estudos futuros, observa-se que não foram considerados outros dados demográficos relevantes como tipo de indústria, processo de manufatura utilizado ou região onde a empresa opera. 0 estudo das relações entre os fatores de satisfação e os segmentos embarcadores por entre diferentes indústrias poderia trazer resultados valiosos para a identificação, por exemplo, de nichos de atuação e para o desenho de serviços de transporte específicos.

\section{Referências}

AGENNCIA NACIONAL DE TRANSPORTE TERRESTRE - ANTT. RNTRC em números. 2011. Disponível em <http:// appeantt.antt.gov.br/ rntrc_numeros/rntrc_total.asp $>$. Acesso em: 25 mai. 2011

AGÊNCIA NACIONAL DE TRANSPORTE TERRESTRE - ANTT. Registro nacional de transportadores rodoviários de cargas - RNTRC. 2008a. Disponível em:<http://www. antt.gov.br/carga/rodoviario/rodoviario.asp $>$. Acesso em: 02 mai. 2008

ARMSTRONG, J.S.; OVERTON, T.S. Estimating nonresponse bias in mail surveys.Journal of Marketing Research, v. 14, p. 396-402, 1997.

BRASIL. Programa de Aceleração do Crescimento - PAC. Disponível em: <http://www.brasil.gov.br/pac/infra estrutura/>. Acesso em: 02 mai. 2008

CANDIDO, J.C.X. O processo de decisão de compra de caminhões pesados. Dissertação (Mestrado em Administração)-Escola de Administração, Universidade Federal do Grande do Sul, 2004.
CENTRO DE ESTUDOS EM LOGÍSTICA - CEL. Transporte de carga no Brasil - Ameaças e oportunidades para o desenvolvimento do país. 2002. Disponível em:<http:// www.centrodelogistica.org/new/fs-pesquisa.htm>. Acesso em: 02 mai. 2008

CHAHAD, J.P.Z.; CACCIAMALl, M.C. As transformações estruturais no setor de transporte rodoviário e a reorganização no mercado de trabalho do motorista de caminhão no Brasil. Revista da ABET, v. 2, n. 10, 2005.

CHOPRA, S.; MEINDL, P. Gerenciamento da cadeia de suprimentos: Estratégia, planejamento e operação. São Paulo: Prentice-Hall, 2006.

CONFEDERAÇÃO NACIONAL DO TRANSPORTE - CNT.Plano CNT de Logística. 2011. Disponível em:<www.cnt.org.br/ Paginas/Plano-CNT-de-Logistica.aspx>. Acesso em: 25 mai. 2011.

COOK, C.; HEATH, F.; THOMPSON, R.L. A meta-analysis of response rates in web- or internet-based surveys. Educational and Psychological Measurement, v. 60, n. 6, p. 821-836, 2000. http://dx.doi. org/10.1177/00131640021970934

FIELD, A. Discovering statistics using SPSS. Londres: Sage Publications, 2005.

FLEURY, P. F. Gestãoestratégica do transporte. In: FIGUEIREDO, K.F.; FLEURY, P.F.; WANKE, P. Logística e gerenciamento da cadeia de suprimentos: planejamento do fluxo de produtos e dos recursos. São Paulo: Editora Atlas, 2003a.

FLEURY, P. F. Panorama do transporte de cargas no Brasil. In: FIGUEIREDO, K.F.; FLEURY, P.F.; WANKE, P. Logística e gerenciamento da cadeia de suprimentos: planejamento do fluxo de produtos e dos recursos. São Paulo: Editora Atlas, 2003b.

GAMEIRO, A. H.; CAIXETA FILHO, J.V. Administração de Seguros no Transporte de Cargas. RAE-eletrônica, v. 1, n. 1, 2002. http://dx.doi.org/10.1590/ S1676-56482002000100009

GIBSON, B. J.; RUTNER, S.M.; KELLER, S. B. Shipper-carrier partnership issues, rankings and satisfaction. International Journal of Physical Distribution \& Logistics Management, v. 32, n. 8, p. 669-681, 2002. http:// dx.doi.org/10.1108/09600030210444917

HAIR, J. F.; ANDERSON, R.E.; TATHAM, R.L. Análise multivariada de dados. Porto Alegre: Bookman, 2005.

HART, 0.; MOORE, J. Property rights and the nature of the firm. Journal of Political Economy, n. 98, p. 1119-1158, 1990. http://dx.doi.org/10.1086/261729http://dx.doi. org/10.1086/261729

HOPKINS, S. A. et al. Service quality gaps in the transportation industry: An empirical investigation. Journal of Business Logistics, v. 14, n. 1, p. 145-161,1993.

INTERNATIONAL LABOR ORGANIZATION- ILO.The scope of the employment relationship. Genebra: International Labor Office, 2003.91. Session, Report 5, Fifth Item on the Agenda.

MALHOTRA, N. K. Pesquisa de marketing: uma orientação aplicada. Porto Alegre: Bookman, 2001.

MENTZER, J. T.; FLINT, D.J. Validity in logistics research. Journal of Business Logistics, v. 18, n. 1, p. 199-216, 1997.

MENTZER, J. T.; FLINT, D.J.; HULT, T.M. Logistics service quality as a segment-customized process.Journal of 
Marketing, v. 65, n. 4, p. 82-104, 2001. http://dx.doi. org/10.1509/jmkg.65.4.82.18390

NAZÁR10, P. Papel do transporte na estratégia logística. In: FLEURY, P.F.; WANKE, P.; FIGUEIREDO, K. F. Logística empresarial: a perspectiva brasileira. São Paulo: Editora Atlas, 2000.

NICKERSON, J. A.; SILVERMAN, B. S. Why aren't all truck drivers owner-operators? Asset ownership and the employment relation in interstate for-hire trucking. Journal of Economics \& Management Strategy, v. 12, n. 1, p. 91-118, 2003. http://dx.doi. org/10.1162/105864003321220742

RODRIGUES, A. M.; STANK, T.P.; LYNCH, D. F. Linking strategy, structure, process, and performance in integrated logistics. Journal of Business Logistics, v. 25, n. 2, p. 65-94, 2004. http://dx.doi.org/10.1002/j.2158-1592.2004.tb00182.x

SHARMA, S. Applied multivariate techniques. New York: John Wiley \& Sons Inc., 1996.
VAlENTE, A. M.; PASSAGliA, E.; NOVAES, A. G. Gerenciamento de transporte e frotas.São Paulo: Pioneira, 1997.

WANKE, P.; ARKADER, R.; HIJJAR, M. F. Logistics sophistication, manufacturing segments and the choice of logistics providers. International Journal of Operations \& Production Management, v. 27, n. 5, p. 542-559, 2007. http://dx.doi.org/10.1108/01443570710742401

WITTE, R.S.; WITTE, J.S. Estatística.Rio de Janeiro: LTC, 2005.

YOSHIDA, E. 0 ano da infra-estrutura. Anuário Exame Infra-Estrutura 2007-2008, nov2007.

\section{Agradecimento}

Pesquisa financiada com recursos da FAPERJ, projeto número E-26/103.286/2011 - Bolsa Jovem Cientista do Nosso Estado.

\section{Abstract}

\section{Satisfaction factors with the use of for-hire trucking in road transportation}

In Brazil, cargo transportation services are predominantly based on truckloads and are dependent mostly on for-hire trucking. This paper reports on a survey conducted with 105 carriers - listed at "Exame - Melhores e Maiores" magazine ranking - to evaluate the major factors related to the satisfaction with the services provided, and also to cluster carriers in terms of common requirements of transportation services. Results indicate three major groups of carriers, in which the service quality perceptions depend on the intensive use of for-hire trucking, the aggregate volume transported per year, and the shipments required safety levels.

\section{Keywords}

Factors. Satisfaction. Cargo transportation. For-hire trucking. Segmentation. 